\title{
Is the observed NAO variability during the instrumental record unusual?
}

\author{
Vladimir A. Semenov, ${ }^{1,2}$ Mojib Latif, ${ }^{1}$ Johann H. Jungclaus, ${ }^{3}$ and Wonsun Park ${ }^{1}$ \\ Received 12 January 2008; revised 24 March 2008; accepted 29 April 2008; published 5 June 2008.
}

[1] Observed multidecadal variability (30 yr running means, trends, and moving standard deviations) of the North Atlantic Oscillation (NAO) during the instrumental record is compared to that simulated by two different coupled general circulation models in extended-range control experiments. Simulated NAO exhibits strong low frequency fluctuations, even on multi-centennial time scale. Observed multi-decadal NAO variations agree well with the model variability. Trend probability distribution functions, observed and simulated, were not found to be different with statistical significance. Thus, multi-decadal NAO changes similar to those observed during the instrumental record, including the recent increase in 1965-1995, may be internally generated within the coupled atmosphere-ocean system without considering external forcing. Citation: Semenov, V. A., M. Latif, J. H. Jungclaus, and W. Park (2008), Is the observed NAO variability during the instrumental record unusual?, Geophys. Res. Lett., 35, L11701, doi:10.1029/2008GL033273.

\section{Introduction}

[2] The North Atlantic Oscillation (NAO), the dominant mode of large-scale wintertime atmospheric variability in the North Atlantic/European sector [Walker, 1924; van Loon and Rogers, 1978], has received a lot of attention due to its strong impact on climate variability in the northern ExtraTropics. In particular, European surface air temperatures (SAT) and precipitation are strongly related to the NAO [Hurrell, 1995]. The NAO experienced significant decadal and multi-decadal changes during the 20th century that were reflected in different components of the climate system (see, e.g., Hurrell et al. [2003] for a review).

[3] The strongest NAO trend during the instrumental period was observed during 1965-1995 (Figure 1a). In the presence of strong global climate change during the last half of the 20th century, it is tempting to explain the NAO trend by forcing external to the atmosphere. A number of studies linked the NAO trend to North Atlantic (NA) and/or tropical sea surface temperatures (SSTs), which exhibited similar contemporaneous changes. Atmosphere model simulations show SSTs (local or remote) may have driven the decadal to multi-decadal NAO changes (see, e.g., Hoerling et al. [2004] for a review). However, some models contradict each other on the relative roles of local and remote forcing, while others do not reproduce the NAO trend at all

\footnotetext{
${ }^{1}$ Leibniz Institute of Marine Sciences at the University of Kiel, IFMGEOMAR, Kiel, Germany.

${ }^{2}$ Obukhov Institute of Atmospheric Physics, RAS, Moscow, Russia.

${ }^{3}$ Max Plank Institute for Meteorology, Hamburg, Germany.

Copyright 2008 by the American Geophysical Union. 0094-8276/08/2008GL033273
}

[e.g., Schneider et al., 2003]. Furthermore, most model studies concentrate only on the second half of the 20th century (covered by reanalysis) and simulated NAO trends are too weak. Thus, the results should be treated with caution [Bretherton and Battisti, 2000].

[4] In Figure 1, the NAO index is shown together with an Indian Ocean SST index $\left(15^{\circ} \mathrm{S}-15^{\circ} \mathrm{N}, 40^{\circ} \mathrm{E}-100^{\circ} \mathrm{E}\right)$, as by Hoerling et al. [2004], and an index of the NA SST tripole regression pattern associated with the NAO [e.g., Rodwell et al., 1999], calculated by regressing detrended SST against the NAO index for 1950-2004. The NA SST tripole index was computed as the scalar product between a regression pattern and SST anomalies in the region $10^{\circ} \mathrm{N}-70^{\circ} \mathrm{N}$, $80^{\circ} \mathrm{W}-0^{\circ} \mathrm{W}$. The positive NAO trend during $1965-1995$ was accompanied by a warming of the Indian Ocean. The downward NAO trend during 1910-1940, however, was also accompanied by a positive SST trend in the Indian Ocean comparable in magnitude to the recent warming. Thus, no robust link seems to exist when considering the whole 20th century. Furthermore, the NA SST tripole regression index for 1950-2004 is representative only for the time after 1960. For the earlier period no robust connection is seen either. This is a simple illustration of some questions that remain after attributing the recent NAO changes to SST forcing.

[5] A shift to the positive NAO phase is generally simulated in (anthropogenic) climate change experiments, although the changes are rather small amounting to only $10-15 \%$ of the standard deviation [Kuzmina et al., 2005; Stephenson et al., 2006]. Corresponding global warming in these simulations, however, is much stronger than the 20th century temperature rise. Transient climate change integrations assuming the moderate Intergovernmental Panel on Climate Change (IPCC) scenario B1, for instance, yield a range of global warming of about $1.2^{\circ} \mathrm{C}$ to $2.4^{\circ} \mathrm{C}$ (with an average of $1.76^{\circ} \mathrm{C}$ ) at the end of 21 st century [IPCC, 2007], which is at least 3 times larger than the global warming observed since $1950 \mathrm{~s}\left(0.4^{\circ} \mathrm{C}\right)$. Given the relatively small change of the NAO in climate change experiments, a potential anthropogenic induced NAO change during the 20th century is unlikely to be detected against the strong background noise.

[6] The instrumental NAO record basically consists of only one realization of the multi-decadal variability (Figure 1). One way to estimate the level of natural variability on multi-decadal time scales is to make use of long simulations with realistic coupled general circulation models (GCMs) run in a "control" setup, i.e. without external forcing. So far, not many simulations exceeding 1000 years were performed. The NAO in millennium control simulations is considered, for instance, by Osborn et al. [1999], Collins et al. [2001], and Min et al. [2005]. Here, the NAO variability is 


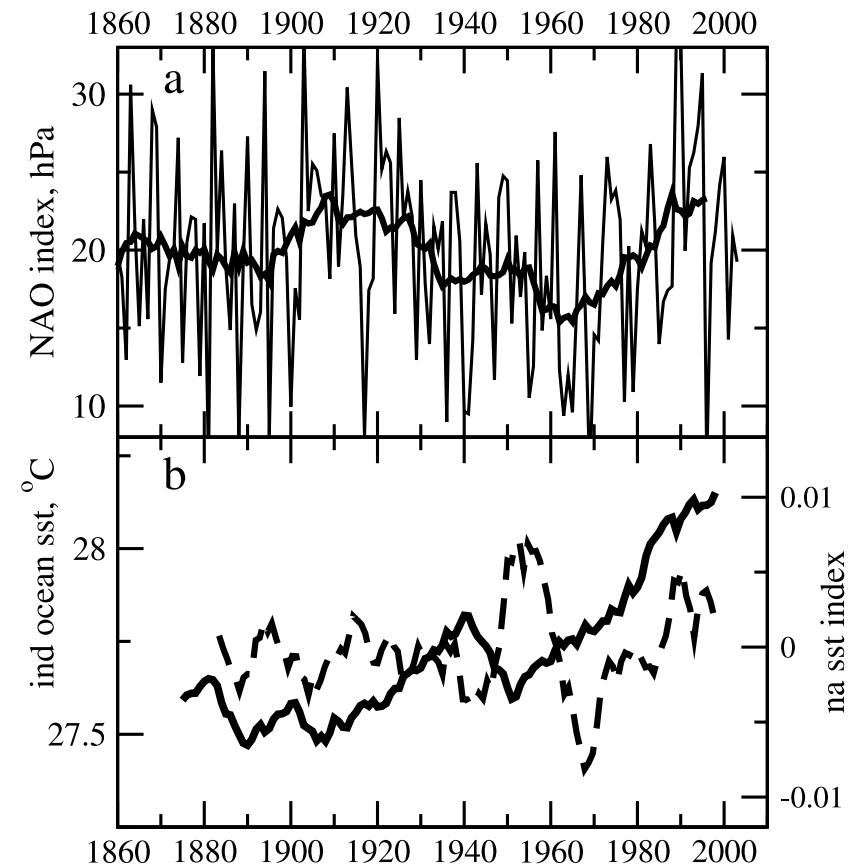

Figure 1. (a) The observed NAO index (DJFM SLP difference $[\mathrm{hPa}]$ between Gibraltar and Reykjavik [Jones et al., 1997]. The thick line is the 15 -year running means. (b) Indian Ocean SST index $(15 \mathrm{~S}-15 \mathrm{~N}, 40 \mathrm{E}-100 \mathrm{E}$ average, 15-year running means, solid line), and index of the NA SST regression pattern (15-year running means, dashed; see text for details).

analyzed in control simulations with two other coupled GCMs, ECHAM5/MPI-OM and Kiel Climate Model $(\mathrm{KCM}), 1500$ years and 3150 years long, respectively. We focus on the multi-decadal changes of the NAO characteristics and address the question of how unusual were the NAO trends during the observational record by applying a test on probability distribution functions.

\section{Models and Data}

[7] Two coupled atmosphere-ocean GCMs are used in this study. The first is ECHAM5/MPI-OM (hereafter referred to as MPI) [Jungclaus et al., 2006], and the other is the Kiel Climate Model, KCM (W. Park et al., Tropical Pacific climate and its response to global warming, submitted to Journal of Climate, 2008). Both models use the atmospheric GCM ECHAM5 [Roeckner et al., 2003] run at a spectral resolution of T31, corresponding to a horizontal resolution of about $3.75^{\circ} \times 3.75^{\circ}$, and with 19 vertical levels. The two atmospheric model versions used in the simulations with MPI and KCM differ in the cloud parameterization scheme [Roeckner et al., 2003]. MPI employs the ocean model MPI-OM [Marsland et al., 2003]. This is a primitive equation model (z-level, free surface) on a C-grid with variable horizontal resolution between $20 \mathrm{~km}$ in high latitudes and about $350 \mathrm{~km}$ in the Tropics, and 40 vertical levels. KCM uses the oceanic GCM NEMO [Madec, 2006]. It is also a z-coordinate model (31 vertical levels) with partial bottom cells and a free surface formulation. The horizontal resolution is based on a $2^{\circ}$ Mercator mesh and is on average $1.3^{\circ}$, with enhanced meridional resolution of $0.5^{\circ}$ close to the equator (ORCA2).

[8] Both coupled atmosphere-ocean GCMs do not employ flux adjustments or any other corrections. The MPI and KCM control simulations are of 1700 and 3750 year duration, respectively. To account for spin-up, only the last 1500 years of the MPI and 3150 years of the KCM simulation are analyzed. Some examples of the models' ability to realistically simulate the internal variability are given by Semenov and Latif [2006] and Dommenget et al. [2006].

[9] Here we use absolute sea level pressure (SLP) difference between Gibraltar and Reykjavik averaged for December through March (DJFM) as the NAO index. This index, starting in 1824, is the longest time series based on instrumental observations [Jones et al., 1997]. The data for 1824-2003 are available from the Climate Research Unit (CRU, http://www.cru.uea.ac.uk/cru/data/nao.htm).

[10] Ability of the models to realistically simulate atmospheric variability in the northern Extra-Tropics was validated using NCEP reanalysis (1949-2006) [Kalnay et al., 1996]. The longer historical (gridded) SLP dataset HadSLP (1850-2004) [Allan and Ansell, 2006] was not used as these data systematically exhibit about $20 \%$ less interannual variability than NCEP. Standard deviations of the DJFM SLP for NCEP and the models are shown in the Figure 2. Both models simulate SLP variability patterns consistent with NCEP. Although the simulated variability is overestimated by the models in the North Pacific and underestimated over Asia and the Tropical Atlantic, no statistically significant disagreement (according to an F-test) is found in the North Atlantic Sector. The standard deviation of the NAO index amounts to $6.3 \mathrm{hPa}$ in station data, $6.8 \mathrm{hPa}$ in NCEP, $5.1 \mathrm{hPa}$ in HadSLP, $6.4 \mathrm{hPa}$ in MPI, and $6.7 \mathrm{hPa}$ in $\mathrm{KCM}$.

\section{Results}

[11] Running 30-year means, trends, and standard deviations (in a sliding 30-year window) of the NAO index as computed from observations and model simulations are analyzed. Only the results of the longer KCM simulation are shown in Figure 3. The MPI simulation provides a very similar picture and will be discussed later in the context of the trend distributions. The observed 30-yr running mean NAO changes are within the variability range simulated in the KCM control experiment (Figure 3a). The simulated NAO index exhibits several realizations that are similar to the observed multi-decadal fluctuations. Even on the centennial time scale, the simulated NAO variability reveals strong changes. We note, for example, a strong secular decrease around the model year 4800 , or exceptionally high values around the year 2900 .

[12] The moving 30-year trends are depicted in Figure 3b. The strongest observed positive trend is slightly exceeded once during the KCM simulation. Although the strongest observed trend $(0.40 \mathrm{hPa} / \mathrm{yr})$ corresponds to the extreme outliers of the simulated trends (exceeding the $99 \%$ percentile; see Figure $3 b$ ), the simulated trend variability, e.g. during the first 500 years, looks similar to the observed. 
a) NCEP

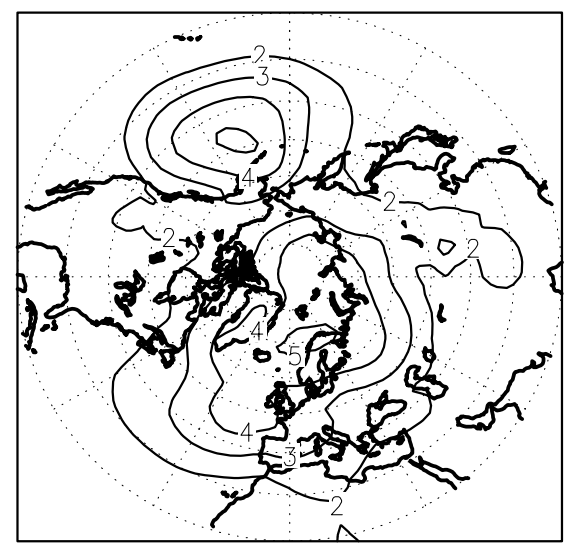

b) $\mathrm{KCM}$

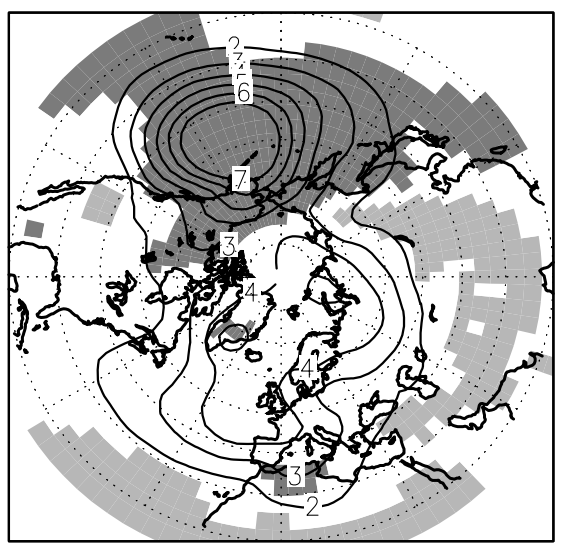

c) MPI

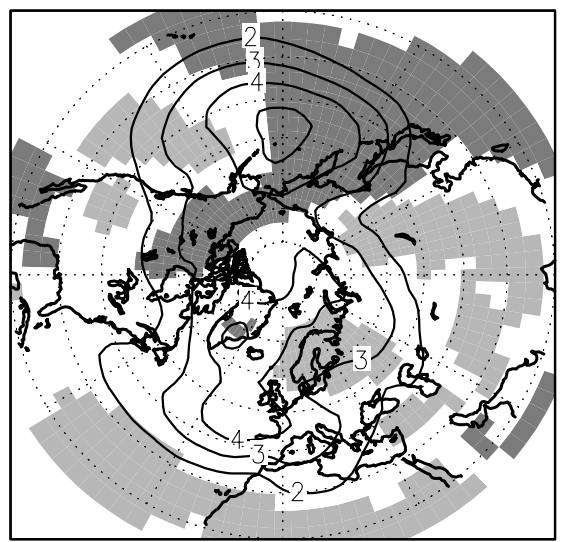

Figure 2. Standard deviation of the DJFM SLP variability $[\mathrm{hPa}]$ from (a) NCEP, (b) KCM, and (c) MPI. The shading shows regions where variability ratio model/NCEP is statistically larger (dark shading) or lower (light shading) at the $95 \%$ confidence level according to an F-test.

Furthermore, one should also consider the simulated negative trends, which exceed the strongest observed trend in terms of absolute amplitude in several cases.

[13] It was found that the variance of the NAO also increased with the recent positive trend [Feldstein, 2002]. The role of global warming in this observation remains speculative. The moving 30-year standard deviations (STD) of the simulated NAO index ranges from $3.8 \mathrm{hPa}$ to $9.6 \mathrm{hPa}$ encompassing the observed changes and exhibit strong long-term variability (Figure 3c). The time-mean STDs for the whole periods are, however, very close, with $6.3 \mathrm{hPa}$ and $6.8 \mathrm{hPa}$ for the observed and model index, respectively. A comparison with the smoothed NAO index (Figure 3a) does not reveal any noticeable link to the variance (no significant correlation is found between running means and STD).

[14] An externally forced nature of the observed positive NAO trend was inferred in several studies [e.g., Osborn et al., 1999; Collins et al., 2001; Feldstein, 2002; Min et al., 2005] through comparison with trend distributions obtained

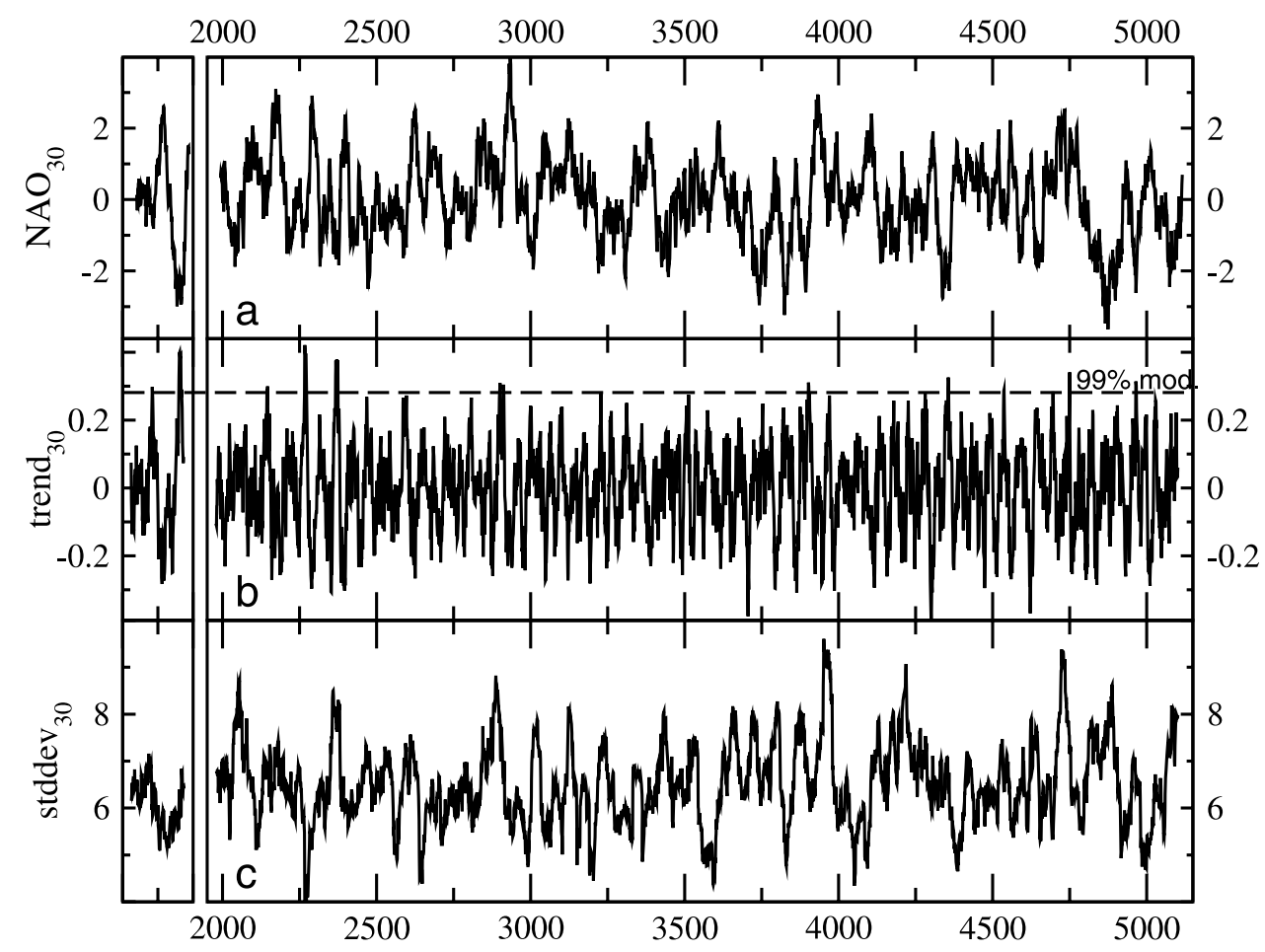

Figure 3. (a) The 30-year running means of the NAO index $[\mathrm{hPa}]$ as (left) observed and (right) simulated by KCM, (b) moving 30-year trends [hPa/yr] (dashed line is the $99 \%$ percentile of the model trend distribution), and (c) standard deviation of the NAO index $[\mathrm{hPa}]$ in a moving 30-year window. 


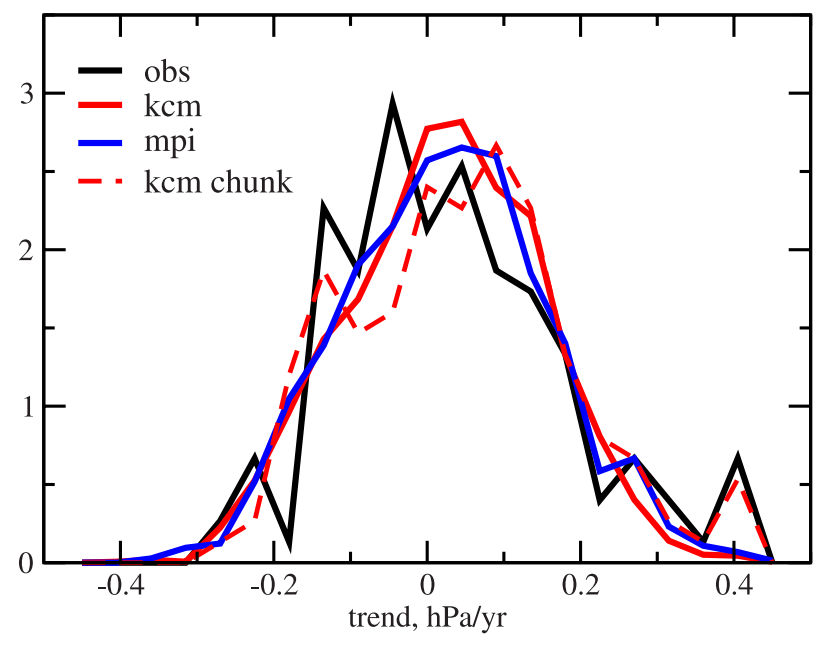

Figure 4. Probability density functions (histograms) of the observed (black), KCM (red solid), and MPI (blue) simulated 30-year moving NAO trends. The dashed red histogram is for a particular 170 year chunk from the KCM simulation (model years 2131-2280).

from control climate model simulations or statistical models. The null hypothesis that the observed trend was an expression of stochastic natural variability was rejected based on a rare occurrence (or absence) of the largest observed trend among simulated values or, for instance, a location of the observed trend beyond the $95 \%$ percentile of the model trend distribution. However, models simulate multi-decadal variations in NAO regimes rather similar to the observed changes in the last two centuries (Figure 3). Thus, we shall test not the unusualness of the strongest observed trend in comparison to the simulated trend distribution, but the unusualness of the observed trend distribution for the whole observational period. When looking at the probability density functions (PDFs) of the observed and simulated 30-year trends (Figure 4), it is hard to conclude with high confidence that they may not be drawn from the same distribution. Rather, taking into account the short length of the observational record, the differences may be caused just by under-sampling. Extreme positive outliers look as suspicious as a jagged behavior around zero or a drop at about -0.2 . This is illustrated by the KCM trend distribution for model years 2131-2280 (same length as observed NAO), which also shows an upper tail spike.

[15] In order to objectively test the difference between the observed and model PDFs, a Kolmogorov-Smirnov test (K-S) [e.g., D'Agostino and Stephens, 1986] is applied, measuring the maximum difference between two empirical distribution functions. The null hypothesis tested is that observed and model distributions are not different or equivalently that observed and model samples are drawn from the same distribution. The K-S test returns probabilities ( $p$ values) of 0.39 and 0.62 for KCM and MPI, respectively (small $p$ values are required to reject the null hypothesis). Thus the null hypothesis in our case may not be rejected. The moving 30-year observed trend distribution, however, contains only six fully independent points. The $\mathrm{K}-\mathrm{S}$ test was applied also to the distributions of moving, consecutive and overlapping trends of 30 and 20 year lengths. The results were found to depend on the method used to construct the PDFs. However, the test also does not yield significance levels less than 0.2.

\section{Discussion}

[16] It is shown that the long-term NAO changes observed during the instrumental record including the recent strongest positive trends may be reproduced in control (without external forcing) simulations with coupled atmosphere-ocean GCMs (Figure 3). Simulated NAO indices exhibit significant changes on multi-decadal and even multi-centennial time scales. This strongly suggests that longer millennium time scale control simulations (at least of several thousand years) are needed in order to infer the range of natural NAO variability, and longer and reliable NAO reconstructions from paleo archives are very important. These conclusions are crucially dependent on the models' ability to realistically simulate real climate variability. Here, we base our confidence in the model results on a reasonable agreement of the simulated DJFM SLP variability in comparison to the NCEP reanalysis (Figure 2). The largest observed trend exceeds the $99 \%$ percentile of the simulated trend distribution for both control simulations considered here, confirming a very low probability of such a trend. In this respect, our results do not contradict other studies. We choose, however, a different perspective to interpret the unusualness of the long-term observed NAO changes. Based on a goodness-of-fit test applied to the observed and simulated trend distributions, we argue that the null hypothesis that the observed sample of climatic NAO trends and simulated trends (by the KCM and MPI models) are drawn from the same distribution may not be rejected. This is in agreement with conclusions by Wunsch [1999] and Jung et al. [2003], who tested the recent NAO changes against the "white noise" null hypothesis. The result, however, does not disprove the hypothesis of external forcing, which is not considered here.

[17] Acknowledgments. The authors would like to thank two anonymous reviewers and Dr. Noel Keenlyside for valuable comments. This work was supported by the Sonderforschungsbereich 460 of the German Science Foundation (DFG), the European Union's DYNAMITE project, and the Russian Foundation for Basic Research. The model runs were performed at the German Climate Computing Center (DKRZ) and the Computing Center at Kiel University.

\section{References}

Allan, R. J., and T. J. Ansell (2006), A new globally complete monthly historical mean sea level pressure data set (HadSLP2), 1850-2004, J. Clim., 19, 5816-5842.

Bretherton, C. S., and D. S. Battisti (2000), An interpretation of the results from atmospheric general circulation models forced by the time history of the observed sea surface temperature distribution, Geophys. Res. Lett., 27, $767-770$.

Collins, M., S. F. B. Tett, and C. Cooper (2001), The internal climate variability of HadCM3, a version of the Hadley Centre coupled model without flux adjustments, Clim. Dyn., 17, 61-81.

D'Agostino, R. B., and M. A. Stephens (1986), Goodness-of-Fit Techniques, 560 pp., Marcel Dekker, New York.

Dommenget, D., V. Semenov, and M. Latif (2006), Impacts of the tropical Indian and Atlantic oceans on ENSO, Geophys. Res. Lett., 33, L11701, doi:10.1029/2006GL025871.

Feldstein, S. B. (2002), The recent trend and variance increase of the annular mode, J. Clim., 15, 88-94.

Hoerling, M. P., J. W. Hurrell, T. Xu, G. T. Bates, and A. S. Phillips (2004), Twentieth century North Atlantic climate change. Part II: Understanding the effect of Indian Ocean warming, Clim. Dyn., 23, 391-405. 
Hurrell, J. W. (1995), Decadal trends in the North Atlantic Oscillation: Regional temperatures and precipitation, Science, 269, 676-679.

Hurrell, J. W., Y. Kushnir, G. Ottersen, and M. Visbeck (Eds.) (2003), The North Atlantic Oscillation: Climate Significance and Environmental Impact, Geophys. Monogr. Ser., vol. 134, AGU, Washington, D. C.

Intergovernmental Panel on Climate Change (IPCC) (2007), Climate Change 2007: The Physical Science Basis, Contribution of Working Group I to the Fourth Assessment Report of the IPCC, Cambridge Univ. Press, U. K.

Jones, P. D., T. Jonsson, and D. Wheeler (1997), Extension to the North Atlantic Oscillation using early instrumental pressure observations from Gibraltar and south-west Iceland, Int. J. Climatol., 17, 1433-1450.

Jung, T., M. Hilmer, E. Ruprecht, S. Kleppek, S. K. Gulev, and O. Zolina (2003), Characteristics of the recent eastward shift of interannual NAO variability, J. Clim., 16, 3371-3382.

Jungclaus, J. H., M. Botzet, H. Haak, N. Keenlyside, J. J.-Luo, M. Latif, J. Marotzke, U. Mikolajewicz, and E. Roeckner (2006), Ocean circulation and tropical variability in the coupled model ECHAM5/MPI-OM, J. Clim., 19, 3952-3972.

Kalnay, E., et al. (1996), The NCEP/NCAR 40-ear reanalysis project, Bull. Am. Meteorol. Soc., 77, 437-470.

Kuzmina, S. I., L. Bengtsson, O. M. Johannessen, H. Drange, L. P. Bobylev, and M. W. Miles (2005), The North Atlantic Oscillation and greenhouse-gas forcing, Geophys. Res. Lett., 32, L04703, doi:10.1029/2004GL021064.

Madec, G. (2006), NEMO reference manual, ocean dynamics component: NEMO-OPA. Preliminary version. Note Pole Model. 27, Inst. PierreSimon Laplace, Paris.

Marsland, S. J., H. Haak, J. H. Jungclaus, M. Latif, and F. Roeske (2003), The Max-Planck-Institute global ocean/sea ice model with orthogonal curvilinear coordinates, Ocean Modell., 5, 91-127.

Min, S.-K., S. Legutke, A. Hense, and W.-T. Kwon (2005), Internal variability in a $1000 \mathrm{yr}$ control simulation with the coupled climate model ECHO-G: II. El Nino Southern Oscillation and North Atlantic Oscillation, Tellus, Ser. A, 57, 622-640.
Osborn, T. J., K. R. Briffa, S. F. B. Tett, P. D. Jones, and R. M. Trigo (1999), Evaluation of the North Atlantic Oscillation as simulated by a coupled climate model, Clim. Dyn., 15, 685-702.

Rodwell, M. J., D. P. Rowell, and C. K. Folland (1999), Oceanic forcing of the wintertime North Atlantic Oscillation and European climate, Nature, 398, 320-323.

Roeckner, E., et al. (2003), The atmospheric general circulation model ECHAM 5. Part I: Model description, Rep. 349, Max Planck Inst. for Meteorol., Hamburg, Germany.

Schneider, E. K., L. Bengtsson, and Z.-Z. Hu (2003), Forcing of Northern Hemisphere climate trends, J. Atmos. Sci., 60, 1504-1521.

Semenov, V. A., and M. Latif (2006), Impact of tropical Pacific variability on the mean North Atlantic thermohaline circulation, Geophys. Res. Lett., 33, L16708, doi:10.1029/2006GL026237.

Stephenson, D. B., V. Pavan, M. Collins, M. M. Junge, R. Quadrelli, and Participating CMIP2 Modelling Groups (2006), North Atlantic Oscillation response to transient greenhouse gas forcing and the impact on European winter climate: A CMIP2 multi-model assessment, Clim. Dyn., 27, 401-420.

van Loon, H., and J. Rogers (1978), The seesaw in winter temperature between Greenland and northern Europe, Part I: General description, Mon. Weather Rev., 106, 296-310.

Walker, G. T. (1924), Correlations in seasonal variations of weather IX, Mem. India Meteorol. Dep., 24, 275-332.

Wunsch, C. (1999), The interpretation of short climate records, with comments on the North Atlantic and Southern oscillations, Bull. Am. Meteorol. Soc., 80, 245-255.

J. H. Jungclaus, Max Plank Institute for Meteorology, Bundesstrasse 53, D-20146 Hamburg, Germany.

M. Latif, W. Park, and V. A. Semenov, Leibniz Institute of Marine Sciences at the University of Kiel, IFM-GEOMAR, Düsternbrooker Weg 20, D-24105 Kiel, Germany. (vsemenov@ifm-geomar.de) 